\title{
MEAN-DRAWDOWN RISK BEHAVIOR: DRAWDOWN RISK AND CAPITAL ASSET PRICING
}

\author{
Mohammad Reza Tavakoli Baghdadabad', Fauzias Mat Nor², \\ Izani Ibrahim ${ }^{3}$
}

National University of Malaysia (UKM), 43600 Bangi, Selangor Darul Ehsan, Malaysia.
E-mail: ${ }^{1}$ Mr_tavakkoli@yahoo.com (corresponding author); ${ }^{2}$ dgsb@ukm.my; ${ }^{3}$ tdgsb@ukm.my

Received 03 February 2012; accepted 06 August 2012

\begin{abstract}
We develop an alternative approach based on mean-drawdown risk behavior versus the mean-variance behavior. We develop two risk measures as the maximum drawdown risk and average drawdown risk to estimate two new betas and then propose two $C A P M$-like models. The data includes a comprehensive universe of more than 11,000 US equity-based mutual funds from first month of 2000 to third month of 2011.

The evidence clearly shows superiority of the maximum and average drawdown betas and their pricing models, the maximum drawdown $C A P M$ and the average drawdown $C A P M$, over the traditional beta and $C A P M$, respectively.
\end{abstract}

Keywords: Mean-maximum drawdown behavior, Mean-average drawdown behavior, Drawdown risk measure, Maximum drawdown beta, Average drawdown beta, Maximum drawdown $C A P M$, Average drawdown $C A P M$.

Reference to this paper should be made as follows: Tavakoli Baghdadabad, M. R.; Nor, F. M.; Ibrahim, I. 2013. Mean-drawdown risk behavior: drawdown risk and capital asset pricing, Journal of Business Economics and Management 14(Supplement 1): S447-S469.

JEL Classification: G12, G15.

\section{Introduction}

The academics and practitioners have been arguing in the competence of capital asset pricing model $(C A P M)$ over the last decades. They have been answering this key question whether beta coefficient is an appropriate risk measure. The majority of these debates concentrate on comparing the ability of this coefficient rather than alternative risk measures to describe the cross section of assets' return (Ang et al. 2002; Estrada 2007; Da 2012). However, majority of these debates overlook where beta as a risk measure comes from equilibrium that investors represent in the mean-variance (MV) behavior. In fact, it comes from an equilibrium in which investors maximize a utility function that depends on mean and variance related to the returns of their portfolio.

However, the variance of returns and its standard deviation is an inappropriate risk measure for two reasons: first, it is a desirable risk measure only when the returns have a symmetric distribution. And second, it can be employed as a risk measure only when 
the distribution of returns is normal. However, both the symmetry and the normality of stock returns are seriously questioned by the empirical evidence on the subject (Chunhachinda et al. 1997; Tee 2009; Dichtl, Drobetz 2011).

Against, the drawdown risk measure (hereafter, $D R M$ ) of returns, which is decomposed to two measures of maximum drawdown risk (hereafter, $M-D R M$ ) and average drawdown risk (hereafter, $A-D R M$ ), is a more acceptable measure of risk for several reasons: first, investors logically prefer downside volatility (Stevenson 2001; Galagedera 2007; Fortin, Hlouskova 2011). Second, unlike the downside risk, the DRM evaluates the loss from a local maximum to the next local minimum and is intuitively appealing for institutional investors (Hamelink; Hoesli 2003, Kim 2010; Schuhmacher, Eling 2011). Third, the $D R M$ is more beneficial than the traditional variance (standard deviation) when the dispersion of returns is asymmetric and just as beneficial when the dispersion is symmetric; accordingly the $D R M$ is better measure of risk in comparison with the variance. And fourth, the $D R M$ is a measure which the information is generated by three statistics of variance, semi-variance, and skewness, thus, it makes possible to utilize alternative single-factor models to estimate the expected returns.

Moreover, the $D R M$ can be utilized to make a replacement behavioral assumption as mean-drawdown behavior (hereafter, $M D B$ ). As described in Hamelink and Hoesli (2003) and Gilli and Schumann (2009), $M D B$ is perfectly correlated to the expected utility and can thus be defended across the same lines utilized by Levy and Markowitz (1979), Markowitz (1991), Eling and Schuhmacher (2007), and Caprin and Lisi (2009).

As main contribution of this study, we propose two alternative risk measures for diversified investors, the $M-D R M$ and $A-D R M$ beta, and two alternative pricing models based on these two risk measures. We also report the evidence from subclasses of US equitybased mutual funds' management styles, which support from the $M-D R M$ and $A-D R M$ beta over the traditional beta, and also the pricing models generated by the $M-D R M$ $(M D-C A P M)$ and the $A-D R M(A D-C A P M)$ over the $C A P M$.

The rest of the paper is organized as follows. Section 1 describes the theoretical and conceptual framework by explaining two approaches of $M V B$ and $C A P M$ on one hand, and $M D B$ and its relevant pricing models on the other hand. Section 2 discusses and reports the empirical evidence which clearly supports the $M-D R M$ and the $A-D R M$ risk measures, the $M-D R M$ and $A-D R M$ beta and their relevant pricing models. Finally, the last section reports some concluding remarks.

\section{1. $M V B$ vs. $M D B$ Framework}

We first explain the $M V B$ framework and its relevant pricing model and then explain our proposed approach as $M D B$ along its relevant pricing models. Then, we explain how to estimate the $M-D R M$ and $A-D R M$ betas. Finally, we compare our suggested pricing models with $C A P M$. 


\section{1. $M V B$ and asset pricing}

The $M V B$ framework explains that an investor's utility (U) is determined by the mean $\left(\mu_{P}\right)$ and variance $\left(\sigma_{P}\right)$ of portfolio returns, where $U=U\left(\mu_{P}, \sigma_{P}\right)$. Thus, the risk of an asset $i$ is assessed by the standard deviation of asset's return $\left(\sigma_{i}\right)$ as:

$$
\sigma_{i}=\sqrt{E\left[\left(R_{i}-\mu_{i}\right)^{2}\right]}
$$

where $R$ and $\mu$ are the return of asset $i$ and mean respectively. However, when asset $i$ is just one out of many in portfolio, its risk is assessed by its covariance with respect to the market portfolio as:

$$
\sigma_{i m}=E\left[\left(R_{i}-\mu_{i}\right)\left(R_{m}-\mu_{m}\right)\right],
$$

where $m$ is the market portfolio. A more useful risk measure can be assessed by dividing this statistic by return's standard deviation of asset $i$ and the market portfolio, thus we estimate asset $i$ 's correlation with respect to the market index as:

$$
\rho_{i m}=\frac{\sigma_{i m}}{\sigma_{i} \cdot \sigma_{m}}=\frac{E\left[\left(R_{i}-\mu_{i}\right)\left(R_{m}-\mu_{m}\right)\right]}{\sqrt{E\left[\left(R_{i}-\mu_{i}\right)^{2}\right] \cdot E\left[\left(R_{m}-\mu_{m}\right)^{2}\right]}} .
$$

Alternatively, the covariance between asset $i$ and the market index can be divided by the variance of the market index, thus asset $i$ 's beta $\left(\beta_{i}\right)$ is calculated as:

$$
\beta_{i}=\frac{\sigma_{i m}}{\sigma_{m}^{2}}=\frac{E\left[\left(R_{i}-\mu_{i}\right)\left(R_{m}-\mu_{m}\right)\right]}{E\left[\left(R_{m}-\mu_{m}\right)^{2}\right]} .
$$

This measure is widely applied in the CAPM pircing model as:

$$
E\left(R_{i}\right)=R_{f}+\beta_{i}\left(R_{m}-R_{f}\right),
$$

where $E\left(R_{i}\right), R_{f}$, and $R_{m}$ denote the expected return on asset $i$, the risk-free rate, and the expected return on the market, respectively. Finaly, variance is a risk measure under symmetric condition.

\section{2. $M D B$ and asset pricing}

\subsection{1. $M-D R M$ framework}

In the $M D B$ framework, investor's utility is $U=U\left(\mu_{M P}, \sum_{M P}^{2}\right)$, where $\sum_{M}^{2}$ denotes the maximum drawdown risk of returns on investor's portfolio. In the $M-D R M$ framework, the risk of an asset $i$ is measured by asset's downside standard deviation on the loss happened from a local maximum to the next local minimum plus the risk premium as:

$$
\sum_{i}=\sqrt{E\left\{\min \left[\left(D_{t-1}+\left(R_{i t}-\mu_{i t}\right), 0\right)\right]^{2}\right\}},
$$

where $D_{0}$ is equal to 0 . $D_{t}$ denotes the maximum loss suffered by an investor from 0 to $t-1$. Eq. (6) is a special case of the semi-deviation with respect to benchmark return $B\left(\sum_{B M i}\right)$ as:

$$
\sum_{B M i}=\sqrt{E\left\{\min \left[\left(D_{t-1}+\left(R_{i t}-B\right), 0\right)\right]^{2}\right\}} .
$$


We denote the $M-D R M$ of fund $i$ as $\sum_{i}^{M}$. In the $M$-DRM framework, the counterpart of fund $i$ 's covariance to market portfolio is computed by the $M-D R M$ covariance as:

$$
\sum_{i M}=E\left\{\min \left[\left(D_{t-1}+\left(R_{i t}-\mu_{i t}\right), 0\right)\right] \cdot \min \left[\left(D_{t-1}+\left(R_{M t}-\mu_{M t}\right), 0\right)\right]\right\} .
$$

Moreover, this co $M-D R M$ is unbounded, but it can also be standardized by dividing it by return's $M-D R M$ of fund $i$ and market index, hence fund $i$ 's $M-D R M$ correlation is obtained as:

$\Theta_{i M}=\frac{\sum_{i M}}{\sum_{i} \cdot \sum_{M}}=\frac{E\left\{\min \left[\left(D_{t-1}+\left(R_{i t}-\mu_{i t}\right), 0\right)\right] \cdot \min \left[\left(D_{t-1}+\left(R_{M t}-\mu_{M t}\right), 0\right)\right]\right\}}{\sqrt{E\left\{\min \left[\left(D_{t-1}+\left(R_{i t}-\mu_{i t}\right), 0\right)\right]^{2}\right\} \cdot E\left\{\min \left[\left(D_{t-1}+\left(R_{M t}-\mu_{M t}\right), 0\right)\right]^{2}\right\}}}$.

The co $M-D R M$ is divided by the market return's $M-D R M$, hence $M-D R M$ beta is obtained as:

$$
\beta_{i}^{M-D R M}=\frac{\sum_{i M}}{\sum_{M}^{2}}=\frac{E\left\{\min \left[\left(D_{t-1}+\left(R_{i t}-\mu_{i t}\right), 0\right)\right] \cdot \min \left[\left(D_{t-1}+\left(R_{M t}-\mu_{M t}\right), 0\right)\right]\right\}}{E\left\{\min \left[\left(D_{t-1}+\left(R_{M t}-\mu_{M t}\right), 0\right)\right]^{2}\right\}} .
$$

The $M-D R M$ beta computes the covariance between the downside returns made by a combination of maximum loss and market risk premium over the investment period. This beta, which is defined as $\beta_{i}^{M-D R M}=\left(\sum_{i} / \sum_{M}\right) \Theta_{i M}$, is described into a $C A P M$-like model in the $M-D R M$ form as:

$$
E\left(R_{i}\right)=R_{f}+\beta_{i}^{M-D R M} .\left(R_{m}-R_{f}\right) .
$$

As defined in Eq. of (5) and (11), our model replaces by the $M-D R M$ beta.

\subsection{2. $A-D R M$ framework}

In the $M D B$ framework, the investor's utility is $U=U\left(\mu_{A P}, \sum_{A P}^{2}\right)$, where $\sum_{A}^{2}$ denotes the average drawdown risk of returns on the investor's portfolio. In the $A-D R M$ framework, the risk of an asset $i$ is assessed by asset's downside standard deviation on the loss happened from a local maximum to the next local minimum plus the risk premium as:

$$
\sum_{i}=\sqrt{E\left\{\min \left[\left(A_{t-1}+\left(R_{i t}-\mu_{i t}\right), 0\right)\right]^{2}\right\}},
$$

where $A_{0}$ is equal to $0 . A_{t}$ denotes the average loss that an investor suffers from 0 to $t-1$. Eq. (12) can be more expressed with respect to any benchmark return $B\left(\sum_{B A i}\right)$ as:

$$
\sum_{B A i}=\sqrt{E\left\{\min \left[\left(A_{t-1}+\left(R_{i t}-B\right), 0\right)\right]^{2}\right\}} .
$$

We denote the $A-D R M$ of fund $i$ simply as $\sum_{i}^{A}$. In the $A$-DRM framework, the counterpart of fund $i$ 's covariance to the market portfolio is resulted by its $A-D R M$ covariance as:

$$
\sum_{i A}=E\left\{\min \left[\left(A_{t-1}+\left(R_{i t}-\mu_{i t}\right), 0\right)\right] \cdot \min \left[\left(A_{t-1}+\left(R_{M t}-\mu_{M t}\right), 0\right)\right]\right\} .
$$


Moreover, it can also be standardized by dividing it by returns' $A-D R M$ of fund $i$ and the returns' $A-D R M$ of market index, hence fund $i$ 's $A-D R M$ correlation $\left(\Theta_{i A}\right)$ is obtained as:

$$
\Theta_{i A}=\frac{\sum_{i A}}{\sum_{i} \cdot \sum_{A}}=\frac{E\left\{\min \left[\left(A_{t-1}+\left(R_{i t}-\mu_{i t}\right), 0\right)\right] \cdot \min \left[\left(A_{t-1}+\left(R_{M t}-\mu_{M t}\right), 0\right)\right]\right\}}{\sqrt{E\left\{\min \left[\left(A_{t-1}+\left(R_{i t}-\mu_{i t}\right), 0\right)\right]^{2}\right\} \cdot E\left\{\min \left[\left(A_{t-1}+\left(R_{M t}-\mu_{M t}\right), 0\right)\right]^{2}\right\}}} .
$$

The co $A-D R M$ can be divided by the market return's $A-D R M$, hence $A-D R M$ is obtained as:

$$
\beta_{i}^{A-D R M}=\frac{\sum_{i A}}{\sum_{A}^{2}}=\frac{E\left\{\min \left[\left(A_{t-1}+\left(R_{i t}-\mu_{i t}\right), 0\right)\right] \cdot \min \left[\left(A_{t-1}+\left(R_{M t}-\mu_{M t}\right), 0\right)\right]\right\}}{E\left\{\min \left[\left(A_{t-1}+\left(R_{M t}-\mu_{M t}\right), 0\right)\right]^{2}\right\}} .
$$

The $A-D R M$ beta computes the covariance between the downside returns generated by a combination of average loss and market risk premium over the holding period. This beta, which is defined as $\beta_{i}^{A-D R M}=\left(\sum_{i} / \sum_{M}\right) \Theta_{i A}$, is described into a CAPM-like model in the $A-D R M$ form as:

$$
E\left(R_{i}\right)=R_{f}+\beta_{i}^{A-D R M}\left(R_{m}-R_{f}\right) .
$$

As defined in Eq. of (5) and (17), our model replaces the CAPM beta by the $A-D R M$ beta.

\subsection{A brief discussion on the $M-D R M$ and $A-D R M$ beta}

The $M-D R M$ and $A-D R M$ betas given by Eq. (10) and (16) can be estimated in at least three ways: first, through dividing the co $M-D R M$ and the co $A-D R M$ between fund $i$ and the market index given by Eq. (8) and (14). Second, through the $M-D R M$ and the $A-D R M$ of the market index given by Eq. (6) for $i=M$ and Eq. (12) for $i=A$, which are $\beta_{i}^{M-D R M}=\sum_{i M}^{2} / \sum_{M}^{2}$ and $\beta_{i}^{A-D R M}=\sum_{i A}^{2} / \sum_{A}^{2}$. Third, through multiplying the ratio of $M-D R M$ and $A-D R M$ of fund $i$ and the market index, the former given by Eq. (6) and (12) and the next given by Eq. (6) for $i=M$ and Eq. (12) for $i=A$, by the $M-D R M$ and $A-D R M$ correlation between fund $i$ and the market index, given by Eq. (9) and (15), which are $\beta_{i}^{M-D R M}=\left(\sum_{i} / \sum_{M}\right) \Theta_{i M}$ and $\beta_{i}^{A-D R M}=\left(\sum_{i} / \sum_{A}\right) \Theta_{i A}$. Both methods are the same because $\Theta_{i M}=\sum_{i M} /\left(\sum_{i} \cdot \sum_{M}\right)$ and $\Theta_{i A}=\sum_{i A} /\left(\sum_{i} \cdot \sum_{A}\right)$; hence $\beta_{i}^{M-D R M}=\sum_{i M} / \sum_{M}^{2}=\sum_{i} \cdot \sum_{M} \cdot \Theta_{i M} / \sum_{M}^{2}=\left(\sum_{i} / \sum_{M}\right) \Theta_{i M}$ and $\beta_{i}^{A-D R M}=$ $\sum_{i A} / \sum_{A}^{2}=\sum_{i} \cdot \sum_{A} \cdot \Theta_{i A} / \sum_{A}^{2}=\left(\sum_{i} / \sum_{A}\right) \Theta_{i A}$.

Finally, as another clear difference between the two betas, the DRM betas can be computed by regression analysis. Let $y_{m t}=\min \left[\left(D_{t-1}+\left(R_{i t}-\mu_{i t}\right), 0\right)\right]$, $x_{m t}=\min \left[\left(D_{t-1}+\left(R_{M t}-\mu_{M t}\right), 0\right)\right]$, and also $\mu_{m y}$ and $\mu_{m x}$ be the mean of $y_{t}$ and $x_{t}$ for the $M-D R M$. In addition, let $y_{A t}=\min \left[\left(A_{t-1}+\left(R_{i t}-\mu_{i t}\right), 0\right)\right]$, $x_{A t}=\min \left[\left(A_{t-1}+\left(R_{M t}-\mu_{M t}\right), 0\right)\right]$, and also $\mu_{A y}$ and $\mu_{A x}$ be the mean of $y_{t}$ and $x_{t}$ for the $A-D R M$. If a regression model be run with $y_{t}$ as the dependent variable and $x_{t}$ as 
the independent variable (that is, $y_{t}=\lambda_{0}+\lambda_{1} \cdot x_{t}+\varepsilon_{t}$, where $\varepsilon$ is an error term and $\lambda_{0}$ and $\lambda_{1}$ are coefficients to be estimated), the estimate of $\lambda_{1}$ would be as:

$$
\lambda_{1}=\frac{E\left[\left(x_{t}-\mu_{x}\right)\left(y_{t}-\mu_{y}\right)\right]}{E\left[\left(x_{t}-\mu_{x}\right)^{2}\right]} .
$$

Alternatively, as defined in Eqs (10) and (16), $\beta_{i}^{M-D R M}$ and $\beta_{i}^{A-D R M}$ can be computed as:

$$
\begin{aligned}
\beta_{i}^{M-D R M} & =\frac{E\left[x_{t} \cdot y_{t}\right]}{E\left[x_{t}^{2}\right]} \\
\beta_{i}^{A-D R M} & =\frac{E\left[x_{t} \cdot y_{t}\right]}{E\left[x_{t}^{2}\right]} .
\end{aligned}
$$

Thus, the best method for estimating $\beta_{i}^{M-D R M}$ and $\beta_{i}^{A-D R M}$ is to test a linear regression without considering a constant between the independent variable, $x_{t}=\min \left[\left(D_{t-1}+\left(R_{M t}-\mu_{M t}\right), 0\right)\right]$ for the $M-D R M$ and $x_{t}=\min \left[\left(A_{t-1}+\left(R_{M t}-\mu_{M t}\right), 0\right)\right]$ for the $A-D R M$, and the dependent variable, $y_{t}=\min \left[\left(D_{t-1}+\left(R_{i t}-\mu_{i t}\right), 0\right)\right]$ for the $M$ $D R M$ and $y_{t}=\min \left[\left(A_{t-1}+\left(R_{i t}-\mu_{i t}\right), 0\right)\right]$ for the $A-D R M$. They are run by $y_{t}=\lambda_{1} \cdot x_{t}+\varepsilon_{t}$, where $\beta_{i}^{M-D R M}=\lambda_{1}$ and $\beta_{i}^{A-D R M}=\lambda_{1}$.

\subsection{A brief discussion on the $D R M$ risk framework}

The $D R M$ was extended by practitioners who did not base their work on theoretical considerations. Most of the literatures on $D R M$ were found in journals outside of finance (Dacorogna et al. 2001), non-refereed finance journals, and finance journals geared to the investment community (Chekhlov et al. 2005). This measure was gradually used in finance literature as a new risk measure (Alexander, Baptista 2006; Eling, Schuhmacher 2007). The drawdown is the loss incurred over the investment period. It is the loss in perceptual from the prior local maximum to the next local minimum of an investment, which is decomposed into maximum DRM and average DRM (Gilli, Schumann 2009). The $D R M$ is the loss suffered when an asset is bought at a local maximum and sold at the next local minimum and or the worst loss that the portfolio suffers over the investment period (Alexander, Baptista 2006). It is the worst return suffered by an investor, e.g. the return of an investor who buys the fund at the highest price and sells it at the lowest price. Institutional investors often capture $D R M$ as a risk measure to choose a portfolio. The $A-D R M$ also is the average loss suffered over the holding period. It is relevant only if one trades the funds under loss condition (Gilli, Schumann 2009).

The concept of $D R M$ was primarily introduced by Grossman and Zhou (1993) and Dacorogna et al. (2001). They investigated two risk-adjusted measures for investors with risk-averse preferences in the maximum drawdown framework. Hamelink and Hoesli (2004) studied the role of real estate in a mixed-asset portfolio when the maximum drawdown is used instead of the standard deviation. They showed that the maximum drawdown is one of the most natural risk measures, and such a framework can help reconcile the optimal allocations to real securities by institutional investors. Alexander and Baptista (2006), using a drawdown constraint, provided a characteristic of optimal portfolios in the MV framework. Eling and Schuhmacher (2007) used the 
maximum $D R M$ and compared the Sharpe ratio with the $D R M$ measures. Schuhmacher and Eling (2011) asserted that DRMs are as well as Sharpe measure and showed that the location and scale condition are sufficient for expected utility to imply the rankings of drawdown measure. However, literature shows that none of the studies use the DRM in the pricing models

\section{Empirical evidence}

We use the monthly data of US equity-based mutual funds' management styles. The data is extracted from the Morningstar database. The research population includes all the funds available in the database. Our sample includes the monthly returns adjusted by dividend for more than 11,000 funds from first month of 2000 to third month of 2011. The monthly return for the 90-day Treasury bills as free risk return and S\&P500 as market index are extracted from the DataStream. The statistics for all the funds are reported in Table 1.

\subsection{Statistical significance for the total sample}

The first step of our analysis consists of calculations over the whole sample. One statistic (MR) reports the average return of each style, and other statistics report the risk measures. Average returns over the whole sample are summarized by mean monthly arithmetic returns; these estimates are reported in Table 1. The risk measures are three for the $M V B$ (standard deviation, correlation coefficient and beta) and six for the $M D B$ (DRM, $A-D R M$, their correlation coefficients, the $D R M$ betas). An estimate of these measures is calculated over the whole sample. Moreover, since all the styles display positively skewed distributional attributes, this reinforces the use of the DRM models very well.

A correlation matrix containing the six measures and mean returns is displayed in Table 2 where the $D R M$ risk measures ( $D R M, A-D R M$ and their betas) outperform the traditional measures (standard deviation and beta). In fact, the $D R M$ measures and their betas outperform the standard deviation and beta.

Specifically, the relationship between return and risk can be extracted from our regression analysis. We begin by running a cross-sectional linear regression relating mean returns to each of the four surveying risk measures. More precisely:

$$
M R_{i}=\gamma_{0}+\gamma_{1} R M_{i}+u_{i},
$$

where $R M_{i}$ and $M R_{i}$ stand for risk measure and mean return, respectively. $\gamma_{0}$ and $\gamma_{1}$ are coefficients to be estimated, $u_{i}$ is an error term, and $i$ denotes funds. The results of our six regression models are reported in panels A and B of Table 3. Panel A reports the result of OLS regressions, where two regressions describe the existence of heteroskedasticity. Panel B also reports the results of OLS in which statistical significance is reported by White's heteroskedasticity-consistent covariance matrix. The results in both panels are same except for the standard deviation: six risk measures are significant because of explanatory power. As reported in Table 3, the DRM measures outperform two tradi- 


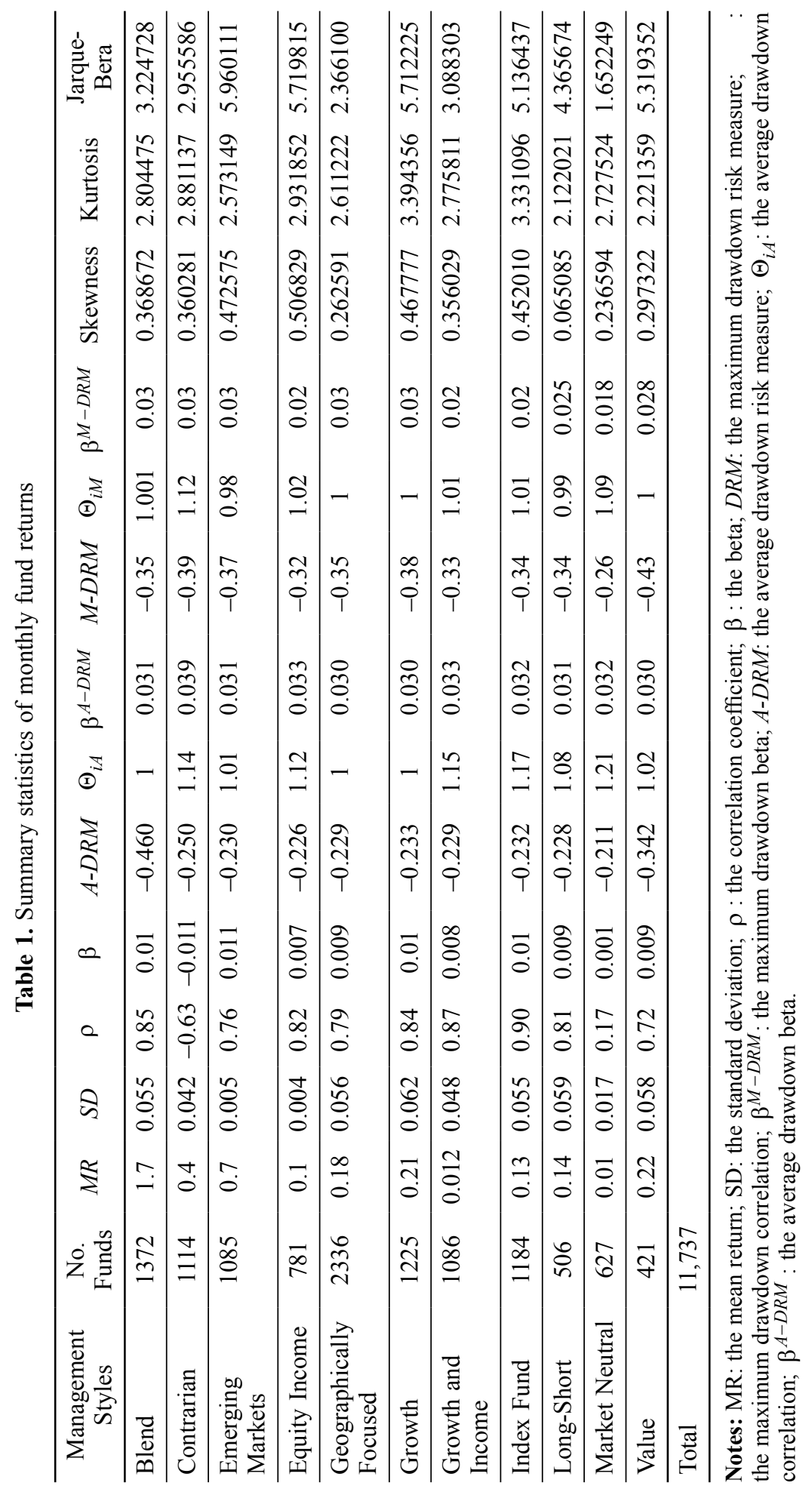


tional measures in terms of their explanatory power. The $D R M$ and $A-D R M$ measures, in fact, outperform the traditional measures and report higher significant coefficient of 0.35 and 0.37 , respectively. Similarly, the $D R M$ and $A-D R M$ betas explain a substantial $38 \%$ and $41 \%$ of the variability respectively in mean returns.

Table 2. Correlation matrix of full sample

\begin{tabular}{lccccccc}
\hline \multicolumn{1}{c}{ Measures } & $M R$ & $S D$ & $M-D R M$ & $A-D R M$ & $\beta$ & $\beta^{M-D R M}$ & $\beta^{A-D R M}$ \\
\hline$M R$ & 1.00 & & & & & & \\
\hline$S D$ & -0.09 & 1.00 & & & & & \\
\hline$M-D R M$ & 0.41 & -0.35 & 1.00 & & & & \\
\hline$A-D R M$ & 0.25 & -0.52 & 0.93 & 1.00 & & & \\
\hline$\beta$ & -0.36 & 0.12 & 0.02 & 0.05 & 1.00 & & \\
\hline$\beta^{M-D R M}$ & -0.13 & -0.34 & 0.66 & 0.75 & 0.22 & 1.00 & \\
\hline$\beta^{A-D R M}$ & 0.20 & 0.53 & -0.32 & -0.54 & -0.04 & -0.50 & 1.00 \\
\hline
\end{tabular}

Notes: MR: the mean return; SD: the standard deviation; $\beta$ : the beta; $D R M$ : the maximum drawdown risk measure; $\beta^{M-D R M}$ : the maximum drawdown beta; $A-D R M$ : the average drawdown risk measure; $\beta^{A-D R M}$ : the average drawdown beta.

Table 3. Simple regression analysis upon full sample

\begin{tabular}{|c|c|c|c|c|c|c|}
\hline \multicolumn{7}{|c|}{$M R_{i}=\gamma_{0}+\gamma_{1} R M_{i}+u_{i}$} \\
\hline$M V$ & $\gamma_{0}$ & t-stat & $\gamma_{1}$ & t-stat & $R^{2}$ & $\operatorname{Adj}-R^{2}$ \\
\hline \multicolumn{7}{|c|}{ Panel A: OLS estimation } \\
\hline$S D$ & 0.019 & 2.014 & -0.592 & -2.18 & 0.09 & 0.07 \\
\hline$\beta$ & 0.012 & 2.87 & -1.16 & -4.77 & 0.14 & 0.14 \\
\hline$M-D R M$ & 0.22 & 4.73 & 0.67 & 12.38 & 0.36 & 0.35 \\
\hline$\beta^{M-D R M}$ & 0.14 & 3.17 & -0.003 & -13.15 & 0.39 & 0.38 \\
\hline$A-D R M$ & 0.31 & 4.89 & 0.72 & 13.01 & 0.39 & 0.37 \\
\hline$\beta^{A-D R M}$ & 0.16 & 3.84 & -0.002 & -14.21 & 0.42 & 0.41 \\
\hline \multicolumn{7}{|c|}{ Panel B: heteroskedasticity-consistent estimation } \\
\hline$S D$ & 0.019 & 2.007 & -0.59 & -1.65 & 0.09 & 0.07 \\
\hline$\beta$ & 0.012 & 4.04 & -1.16 & -3.72 & 0.14 & 0.14 \\
\hline$M-D R M$ & 0.22 & 5.48 & 0.67 & 9.24 & 0.36 & 0.35 \\
\hline$\beta^{M-D R M}$ & 0.14 & 3.08 & -0.003 & -9.2 & 0.39 & 0.38 \\
\hline$A-D R M$ & 0.31 & 4.89 & 0.72 & 13.01 & 0.39 & 0.37 \\
\hline$\beta^{A-D R M}$ & 0.16 & 3.84 & -0.002 & -14.21 & 0.42 & 0.41 \\
\hline
\end{tabular}

Notes: MR: the mean return; RM: the risk measure; SD: the standard deviation; $\beta$ : the beta; $D R M$ : the maximum drawdown risk measure; $\beta^{M-D R M}$ : the maximum drawdown beta; $A-D R M$ : the average drawdown risk measure; $\beta^{A-D R M}$ : the average drawdown beta. 
Table 4 displays the results of three multiple regressions: the standard deviation and the $D R M$; the standard deviation and the $A-D R M$; beta and DRM beta; beta and DRM beta and the four risk measures all together. As shown in the table, when traditional beta and $D R M$ beta are considered together, it is only the latter that comes out significant. This result also is similar to $A-D R M$ beta. When the four risk measures are considered all together, again $D R M$ measures ( $D R M, A-D R M$ and their betas) are only measures that come out significant. In other words, our suggested $D R M$ betas outperform beta in terms of their explanatory power. The average R-squared for the two-factor regressions of "beta and DRM beta" and "beta and $A-D R M$ beta" are 0.43 and 0.48 respectively, which implicate their better significant power. This R-squared for the four-factor regressions, as reported in Panel B of Table 4, are 0.72 and 0.76 .

\subsection{Statistical significance on management styles}

In this section, we consider the management styles and re-assess the significance power of each measure. Note that $D R M$ measures describe skewed distributions of returns better than the traditional measures. If all the distributions be symmetric, the $D R M$ and the standard deviation would contain same information, and $M D B$ would lose most of its appeal as a behavioral model.

Table 5 reports the results of simple regressions splitting the sample into the styles. All the measures perform much better in DRMs than in traditional measures. Both of $D R M$ measures are clearly significant and explain a better explanatory power. This result reinforces the prior findings reported by Hamelink and Hoesli (2004). The R-square coefficients for $D R M$ beta are higher than beta, a range from 0.13 on Emerging Markets to 0.44 on Value. These coefficients for $A-D R M$ beta are ranged from 0.13 to 0.45 . Inversely, these coefficients for the beta are lower than the $D R M$ betas, a range from 0.10 to 0.23 that again implicate the superiority of the $D R M$ betas.

Table 4. Multiple regression analysis upon full sample

\begin{tabular}{lccccccc}
\hline \multicolumn{5}{c}{ Panel A: $M R_{i}=\gamma_{0}+\gamma_{1} R M_{1 i}+\gamma_{2} R M_{2 i}+v_{i}$} \\
\hline$R M_{1} / R M_{2}$ & $\gamma_{0}$ & t-stat & $\gamma_{1}$ & t-stat & $\gamma_{2}$ & t-stat & $R^{2}$ \\
\hline$S D / M-D R M$ & 0.22 & 4.72 & -0.09 & -0.36 & 0.67 & 12.27 & 0.36 \\
\hline$\beta / \beta^{M-D R M}$ & 0.14 & 3.19 & -0.5 & -2.88 & -0.003 & -13.18 & 0.43 \\
\hline$S D / A-A R M$ & 0.31 & 5.01 & -0.06 & -1.24 & 0.71 & 13.19 & 0.43 \\
\hline$\beta / \beta^{A-D R M}$ & 0.20 & 3.89 & -0.44 & -3.26 & -0.002 & -14.20 & 0.48 \\
\hline
\end{tabular}

\begin{tabular}{lccccccccccc}
\hline Panel B: $M R_{i}=\gamma_{0}+\gamma_{1} R M_{1 i}+\gamma_{2} R M_{2 i}+\gamma_{3} R M_{3 i}+\gamma_{4} R M_{4 i}+v_{i}$ \\
\hline$R M_{1} / R M_{2} / R M_{3} / R M_{4}$ & $\gamma_{0}$ & t-stat & $\gamma_{1}$ & t-stat & $\gamma_{2}$ & t-stat & $\gamma_{3}$ & t-stat & $\gamma_{4}$ & t-stat & $R^{2}$ \\
\hline$S D / M-D R M / \beta / \beta^{M-D R M}$ & 0.25 & 14.33 & -0.1 & -0.56 & 0.44 & 12.22 & -0.24 & -1.76 & -0.002 & -13.3 & 0.72 \\
\hline$S D / A-D R M / \beta / \beta^{A-D R M}$ & 0.26 & 14.83 & -0.05 & -0.89 & 0.51 & 12.90 & -0.20 & -2.01 & -0.001 & -13.6 & 0.76 \\
\hline
\end{tabular}

Notes: MR: the mean return; RM: the risk measure; SD: the standard deviation; $\beta$ : the beta; $D R M$ : the maximum drawdown risk measure; $\beta^{M-D R M}$ : the maximum drawdown beta; $A-D R M$ : the average drawdown risk measure; $\beta^{A-D R M}$ : the average drawdown beta. 
Table 5. Management styles: simple regression analysis

\begin{tabular}{|c|c|c|c|c|c|c|}
\hline \multicolumn{7}{|c|}{$M R_{i}=\gamma_{0}+\gamma_{1} R M_{i}+u_{i}$} \\
\hline$M V$ & $\gamma_{0}$ & t-stat & $\gamma_{1}$ & t-stat & $R^{2}$ & $\operatorname{Adj}-R^{2}$ \\
\hline 1 & 2 & 3 & 4 & 5 & 6 & 7 \\
\hline \multicolumn{7}{|c|}{ Panel A: Blend } \\
\hline$S D$ & 0.01 & 1.48 & -0.56 & -1.62 & 0.06 & 0.05 \\
\hline$\beta$ & 0.01 & 2.72 & -1.1 & -4.43 & 0.12 & 0.12 \\
\hline$M-D R M$ & 0.26 & 3.42 & 0.81 & 18.72 & 0.59 & 0.58 \\
\hline$\beta^{M-D R M}$ & 0.16 & 3.46 & -0.003 & -11.61 & 0.30 & 0.29 \\
\hline$A-D R M$ & 0.28 & 4.12 & 0.92 & 20.11 & 0.60 & 0.59 \\
\hline$\beta^{A-D R M}$ & 0.19 & 3.92 & 0.004 & -14.52 & 0.34 & 0.32 \\
\hline \multicolumn{7}{|c|}{ Panel B: Contrarian } \\
\hline$S D$ & -0.02 & -2.77 & 0.35 & 2.86 & 0.58 & 0.57 \\
\hline$\beta$ & -0.02 & -3.47 & -1.39 & -5.11 & 0.16 & 0.15 \\
\hline 1 & 2 & 3 & 4 & 5 & 6 & 7 \\
\hline$M-D R M$ & 0.25 & 2.17 & 0.82 & 30.88 & 0.77 & 0.77 \\
\hline$\beta^{M-D R M}$ & -0.01 & -2.39 & 0.0002 & 3.72 & 0.18 & 0.17 \\
\hline$A-D R M$ & 0.27 & 3.25 & 0.91 & 35.14 & 0.80 & 0.78 \\
\hline$\beta^{A-D R M}$ & -0.009 & -3.39 & 0.0041 & 4.15 & 0.23 & 0.21 \\
\hline \multicolumn{7}{|c|}{ Panel C: Emerging Markets } \\
\hline$S D$ & 0.01 & 1.25 & -0.35 & -0.97 & 0.11 & 0.10 \\
\hline$\beta$ & 0.01 & 3.03 & -1.06 & -4.33 & 0.12 & 0.11 \\
\hline$M-D R M$ & 0.3 & 4.37 & 0.85 & 26.9 & 0.79 & 0.79 \\
\hline$\beta^{M-D R M}$ & 0.016 & 4.07 & -0.0002 & -4.37 & 0.13 & 0.13 \\
\hline$A-D R M$ & 0.33 & 4.56 & 0.91 & 28.41 & 0.80 & 0.79 \\
\hline$\beta^{A-D R M}$ & 0.023 & 4.86 & -0.0001 & -4.89 & 0.15 & 0.13 \\
\hline \multicolumn{7}{|c|}{ Panel D: Equity Income } \\
\hline$S D$ & 0.017 & 2.68 & -0.95 & -4.02 & 0.16 & 0.15 \\
\hline$\beta$ & 0.008 & 2.29 & -1.02 & -4.23 & 0.11 & 0.11 \\
\hline$M-D R M$ & 0.19 & 2.65 & 0.73 & 16.43 & 0.50 & 0.49 \\
\hline$\beta^{M-D R M}$ & 0.11 & 4.09 & -0.002 & -9.46 & 0.19 & 0.18 \\
\hline$A-D R M$ & 0.27 & 3.08 & 0.79 & 19.46 & 0.53 & 0.51 \\
\hline$\beta^{A-D R M}$ & 0.14 & 4.62 & -0.001 & -9.84 & 0.22 & 0.20 \\
\hline \multicolumn{7}{|c|}{ Panel E: Geographically Focused (Equity Funds) } \\
\hline$S D$ & 0.01 & 1.2 & -0.56 & -1.41 & 0.11 & 0.10 \\
\hline$\beta$ & 0.01 & 2.66 & -1.14 & -4.83 & 0.14 & 0.14 \\
\hline
\end{tabular}


Continue of Table 5

\begin{tabular}{lcccccc}
\hline 1 & 2 & 3 & 4 & 5 & 6 & 7 \\
\hline$M-D R M$ & 0.05 & 5.11 & 0.14 & 5.37 & 0.17 & 0.17 \\
\hline$\beta^{M-D R M}$ & 0.06 & 3.73 & -0.001 & -4.79 & 0.16 & 0.15 \\
\hline$A-D R M$ & 0.09 & 5.89 & 0.26 & 6.41 & 0.19 & 0.18 \\
\hline$\beta^{A-D R M}$ & 0.11 & 4.12 & -0.0008 & -4.89 & 0.19 & 0.17 \\
\hline
\end{tabular}

Panel F: Growth

\begin{tabular}{lcccccc}
\hline$S D$ & 0.007 & 0.77 & -0.3 & -0.85 & 0.06 & 0.04 \\
\hline$\beta$ & 0.01 & 2.91 & -1.24 & -4.84 & 0.14 & 0.14 \\
\hline$M-D R M$ & 0.06 & 5.41 & 0.15 & 5.66 & 0.19 & 0.18 \\
\hline$\beta^{M-D R M}$ & 0.17 & 3.29 & -0.004 & -11.12 & 0.27 & 0.26 \\
\hline$A-D R M$ & 0.1 & 5.99 & 0.19 & 6.02 & 0.23 & 0.23 \\
\hline$\beta^{A-D R M}$ & 0.29 & 3.89 & -0.001 & -13.09 & 0.31 & 0.29 \\
\hline
\end{tabular}

Panel G: Growth and Income

\begin{tabular}{lcccccc}
\hline$S D$ & 0.01 & 2.09 & -0.84 & -2.64 & 0.04 & 0.04 \\
\hline$\beta$ & 0.008 & 2.007 & -0.96 & -3.92 & 0.11 & 0.10 \\
\hline 1 & 2 & 3 & 4 & 5 & 6 & 7 \\
\hline$M-D R M$ & 0.03 & 3.9 & 0.102 & 4.27 & 0.12 & 0.11 \\
\hline$\beta^{M-D R M}$ & 0.15 & 3.43 & -0.003 & -11.29 & 0.28 & 0.27 \\
\hline$A-D R M$ & 0.04 & 3.96 & 0.16 & 4.30 & 0.14 & 0.12 \\
\hline$\beta^{A-D R M}$ & 0.17 & 3.62 & -0.002 & -12.11 & 0.29 & 0.28 \\
\hline
\end{tabular}

\begin{tabular}{lcccccc}
\multicolumn{7}{c}{ Panel H: Index Fund (Equity Funds) } \\
\hline$S D$ & 0.01 & 1.23 & -0.52 & -1.3 & 0.06 & 0.04 \\
\hline$\beta$ & 0.01 & 2.73 & -1.13 & -4.71 & 0.14 & 0.13 \\
\hline$M-D R M$ & 0.04 & 4.2 & 0.11 & 4.46 & 0.13 & 0.12 \\
\hline$\beta^{M-D R M}$ & 0.19 & 2.88 & -0.004 & -14.42 & 0.43 & 0.42 \\
\hline$A-D R M$ & 0.05 & 4.33 & 0.15 & 4.75 & 0.15 & 0.14 \\
\hline$\beta^{A-D R M}$ & 0.21 & 2.96 & -0.003 & -14.76 & 0.44 & 0.43 \\
\hline \multicolumn{7}{c}{ Panel I: Long-Short } \\
\hline$D^{A}$ & 0.01 & 1.63 & -0.44 & -1.94 & 0.08 & 0.06 \\
\hline$M-D R M$ & 0.01 & 3.18 & -1.3 & -5.3 & 0.17 & 0.16 \\
\hline$\beta^{M-D R M}$ & 0.1 & 4.31 & -0.002 & -8.18 & 0.18 & 0.17 \\
\hline$A-D R M$ & 0.03 & 4.77 & 0.19 & 4.91 & 0.16 & 0.15 \\
\hline$\beta^{A-D R M}$ & 0.15 & 4.44 & -0.001 & -8.58 & 0.19 & 0.17 \\
\hline
\end{tabular}


End of Table 5

\begin{tabular}{lcccccc}
\hline 1 & 2 & 3 & 4 & 5 & 6 & 7 \\
\hline$S D$ & 0.003 & 2.81 & -0.29 & -3.43 & 0.08 & 0.07 \\
\hline$\beta$ & 0.0005 & 0.71 & -0.7 & -2.63 & 0.24 & 0.23 \\
\hline$M-D R M$ & 0.01 & 2.72 & -1.1 & -4.43 & 0.12 & 0.12 \\
\hline$\beta^{M-D R M}$ & 0.16 & 3.46 & -0.003 & -11.61 & 0.30 & 0.29 \\
\hline$A-D R M$ & 0.02 & 2.88 & -1.6 & -4.81 & 0.14 & 0.12 \\
\hline$\beta^{A-D R M}$ & 0.19 & 3.89 & -0.002 & -11.89 & 0.31 & 0.30 \\
\hline \multicolumn{7}{c}{ Panel J: Market Neutral (Equity Funds) } \\
\hline$S D$ & 0.02 & 1.24 & -0.50 & -1.2 & 0.07 & 0.06 \\
\hline$\beta$ & 0.02 & 2.75 & -1.11 & -4.70 & 0.15 & 0.14 \\
\hline$M-D R M$ & 0.05 & 4.5 & 0.12 & 4.48 & 0.14 & 0.13 \\
\hline$\beta^{M-D R M}$ & 0.20 & 2.98 & -0.003 & -14.38 & 0.45 & 0.44 \\
\hline$A-D R M$ & 0.06 & 4.62 & 0.15 & 4.71 & 0.16 & 0.15 \\
\hline$\beta^{A-D R M}$ & 0.25 & 3.03 & -0.002 & -14.69 & 0.47 & 0.45 \\
\hline
\end{tabular}

Notes: MR: the mean return; RM: the risk measure; SD: the standard deviation; $\beta$ : the beta; $D R M$ : the maximum drawdown risk measure; $\beta^{M-D R M}$ : the maximum drawdown beta; $A$-DRM: the average drawdown risk measure; $\beta^{A-D R M}$ : the average drawdown beta.

Table 6 reports the results of multiple regressions splitting again the sample in the styles. The results confirm that none of the two traditional risk measures have a better significant explanatory power than the $D R M$ measures. The $D R M$ is significant when jointly considered with the standard deviation, and the $D R M$ beta is significant when jointly considered with the beta. Finally, the $D R M$ and its beta are significant when jointly considered with the two other traditional measures in the multi-factor models. Panel A also reports when considering multi-factor models of the beta and the DRM betas, five styles of Growth and Income, Index Fund, Long-Short, Market Neutral and Value have larger R-square than other combinational models. This implicates more significant of the $D R M$ betas in the styles, a range from 0.26 to 0.68 .

\subsection{Economic significance: spreads in return and risk}

To check for the robustness of our results, we divided all the styles into three equallyweighted portfolios classified by beta, and computed the spreads in mean returns between the riskiest portfolio and the least risky portfolio. Then, we repeated the process by ranking the portfolios made by $D R M$ betas and computing again the spread between the riskiest portfolio and the least risky portfolio. By focusing on the joint sample of the styles (Panel A of Table 7), there seems a large difference in the spread of two risk measures of portfolios 1 and 3: the difference between traditional betas is 1.08 and between $D R M$ betas is 1.5 and 1.3. Note, however, that the average beta of portfolio 1 (1.08) is larger than the average beta of portfolio 3 (0), in addition the average DRM 
Table 6. Management styles: multiple regression analysis

\begin{tabular}{|c|c|c|c|c|c|c|c|c|}
\hline \multicolumn{9}{|c|}{ Panel A: $M R_{i}=\gamma_{0}+\gamma_{1} R M_{1 i}+\gamma_{2} R M_{2 i}+v_{i}$} \\
\hline Styles & $R M_{1} / R M_{2}$ & $\gamma_{0}$ & t-stat & $\gamma_{1}$ & t-stat & $\gamma_{2}$ & t-stat & $R^{2}$ \\
\hline \multirow{4}{*}{ Blend } & $S D / M-D R M$ & 0.26 & 3.38 & -0.18 & -0.78 & 0.81 & 18.6 & 0.59 \\
\hline & $\beta / \beta^{M-D R M}$ & 0.17 & 3.43 & -0.58 & -3.09 & -0.003 & -11.9 & 0.34 \\
\hline & $S D / A-A R M$ & 0.27 & 3.40 & -0.19 & -0.88 & 0.82 & 18.89 & 0.60 \\
\hline & $\beta / \beta^{A-D R M}$ & 0.17 & 3.66 & -0.48 & -3.56 & -0.002 & -12.11 & 0.40 \\
\hline \multirow{4}{*}{ Contrarian } & $S D / M-D R M$ & 0.25 & 2.19 & 0.06 & 1.22 & 0.81 & 29.9 & 0.77 \\
\hline & $\beta / \beta^{M-D R M}$ & -0.02 & -4.5 & -1.2 & -4.74 & 0.0001 & 3.08 & 0.22 \\
\hline & $S D / A-A R M$ & 0.27 & 2.34 & 0.17 & 2.13 & 0.89 & 30.12 & 0.78 \\
\hline & $\beta / \beta^{A-D R M}$ & -0.01 & -5.01 & -2.1 & -4.89 & 0.0101 & 3.44 & 0.33 \\
\hline \multirow{4}{*}{$\begin{array}{l}\text { Emerging } \\
\text { Markets }\end{array}$} & $S D / M-D R M$ & 0.09 & 7.04 & 0.01 & 0.05 & 0.24 & 7.05 & 0.28 \\
\hline & $\beta / \beta^{M-D R M}$ & 0.01 & 3.87 & -1.1 & -4.42 & 0.0002 & 4.91 & 0.12 \\
\hline & $S D / A-A R M$ & 0.10 & 6.21 & 0.22 & 0.15 & 0.31 & 7.67 & 0.39 \\
\hline & $\beta / \beta^{A-D R M}$ & 0.21 & 3.25 & -3.25 & -4.88 & 0.0012 & 4.98 & 0.23 \\
\hline \multirow{4}{*}{ Equity Income } & $S D / M-D R M$ & 0.032 & 3.87 & -0.6 & -1.81 & 0.065 & 2.73 & 0.11 \\
\hline & $\beta / \beta^{M-D R M}$ & 0.023 & 2.63 & -0.73 & -2.82 & -0.0003 & -2.07 & 0.15 \\
\hline & $S D / A-A R M$ & 0.041 & 3.94 & -0.51 & -1.99 & 0.101 & 3.36 & 0.20 \\
\hline & $\beta / \beta^{A-D R M}$ & 0.29 & 2.89 & -1.24 & -3.16 & 0.01 & 4.28 & 0.26 \\
\hline \multirow{4}{*}{$\begin{array}{l}\text { Geographically } \\
\text { Focused }\end{array}$} & $S D / M-D R M$ & 0.05 & 4.83 & -0.06 & -0.19 & 0.14 & 5.02 & 0.17 \\
\hline & $\beta / \beta^{M-D R M}$ & 0.065 & 4.007 & -0.67 & -2.98 & -0.001 & -4.53 & 0.21 \\
\hline & $S D / A-A R M$ & 0.07 & 4.99 & -0.05 & -0.26 & 2.14 & 5.44 & 0.31 \\
\hline & $\beta / \beta^{A-D R M}$ & 0.079 & 5.16 & -0.84 & -2.96 & -0.021 & -4.66 & 0.28 \\
\hline \multirow{4}{*}{ Growth } & $S D / M-D R M$ & 0.05 & 4.9 & 0.39 & 1.52 & 0.16 & 5.89 & 0.20 \\
\hline & $\beta / \beta^{M-D R M}$ & 0.03 & 2.66 & -0.86 & -3.12 & -0.0005 & -2.01 & 0.16 \\
\hline & $S D / A-A R M$ & 0.07 & 4.98 & 0.41 & 1.59 & 0.19 & 5.9 & 0.21 \\
\hline & $\beta / \beta^{A-D R M}$ & 0.031 & 2.69 & -0.84 & -3.89 & -0.0011 & -2.66 & 0.17 \\
\hline
\end{tabular}




\begin{tabular}{|c|c|c|c|c|c|c|c|c|}
\hline \multicolumn{9}{|c|}{ Panel A: $M R_{i}=\gamma_{0}+\gamma_{1} R M_{1 i}+\gamma_{2} R M_{2 i}+v_{i}$} \\
\hline Styles & $R M_{1} / R M_{2}$ & $\gamma_{0}$ & t-stat & $\gamma_{1}$ & t-stat & $\gamma_{2}$ & t-stat & $R^{2}$ \\
\hline \multirow{4}{*}{$\begin{array}{l}\text { Growth and } \\
\text { Income }\end{array}$} & $S D / M-D R M$ & 0.03 & 4.05 & -0.39 & -1.17 & 0.09 & 3.48 & 0.12 \\
\hline & $\beta / \beta^{M-D R M}$ & 0.15 & 3.42 & -0.47 & -2.52 & -0.003 & -11.4 & 0.31 \\
\hline & $S D / A-A R M$ & 0.036 & 4.43 & -0.31 & -2.22 & 0.10 & 3.89 & 0.16 \\
\hline & $\beta / \beta^{A-D R M}$ & 0.21 & 3.29 & -0.39 & -2.76 & -0.001 & -13.62 & 0.39 \\
\hline \multirow{4}{*}{ Inde } & $S D / M-D R M$ & 0.04 & 3.89 & -0.14 & -0.44 & 0.11 & 4.2 & 0.13 \\
\hline & $\beta / \beta^{M-D R M}$ & 0.2 & 2.85 & -0.57 & -3.51 & -0.003 & -14.69 & 0.48 \\
\hline & $S D / A-A R M$ & 0.12 & 4.59 & -0.10 & -0.53 & 0.26 & 4.89 & 0.13 \\
\hline & $\beta / \beta^{A-D R M}$ & 0.26 & 2.90 & -0.43 & -3.97 & -0.002 & -15.01 & 0.50 \\
\hline \multirow{4}{*}{ Long-Short } & $S D / M-D R M$ & 0.04 & 4.38 & -0.03 & -0.23 & 0.12 & 4.67 & 0.14 \\
\hline & $\beta / \beta^{M-D R M}$ & 0.03 & 3.14 & -0.96 & -3.4 & -0.0005 & -2.43 & 0.20 \\
\hline & $S D / A-A R M$ & 0.03 & 4.66 & -0.01 & -2.02 & 0.17 & 4.88 & 0.26 \\
\hline & $\beta / \beta^{A-D R M}$ & 0.05 & 3.98 & -0.72 & -4.02 & 0.01 & 2.66 & 0.32 \\
\hline \multirow{4}{*}{$\begin{array}{l}\text { Market Neutral } \\
\text { (Equity Funds) }\end{array}$} & $S D / M-D R M$ & 0.004 & 2.44 & -0.29 & -3.44 & 0.003 & 3.65 & 0.18 \\
\hline & $\beta / \beta^{M-D R M}$ & 0.0002 & 0.23 & -0.73 & -2.67 & 4.34 & 4.49 & 0.25 \\
\hline & $S D / A-A R M$ & 0.02 & 3.11 & -0.10 & -3.91 & 0.021 & 3.99 & 0.29 \\
\hline & $\beta / \beta^{A-D R M}$ & 0.024 & 2.39 & -0.24 & -4.99 & 5.11 & 4.89 & 0.43 \\
\hline \multirow{4}{*}{ Value } & $S D / M-D R M$ & 0.04 & 3.89 & -0.14 & -3.44 & 0.13 & 4.6 & 0.15 \\
\hline & $\beta / \beta^{M-D R M}$ & 0.2 & 2.85 & -0.57 & -3.51 & -0.002 & -13.69 & 0.48 \\
\hline & $S D / A-A R M$ & 0.08 & 4.01 & -0.12 & -3.98 & 0.18 & 4.74 & 0.29 \\
\hline & $\beta / \beta^{A-D R M}$ & 0.31 & 3.99 & -0.36 & -3.87 & 0.014 & 12.74 & 0.68 \\
\hline
\end{tabular}

beta of portfolio $1(1.3)$ is larger than the average $D R M$ beta of portfolio $3(0.02)$ and the average $A-D R M$ beta of portfolio 1 (1.5) is larger than the average $A$-DRM beta of portfolio 3 (0.07). In terms of mean returns, the spread between portfolios 1 and 3 when classified by beta is 0.96 a month ( 0.82 annualized), since the spread between these two portfolios when ranked by $D R M$ betas is a bit larger, 1.29 a month (0.91 annualized). 


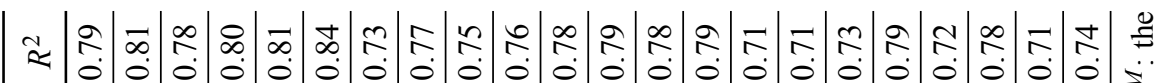

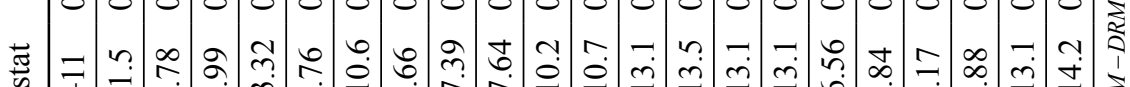

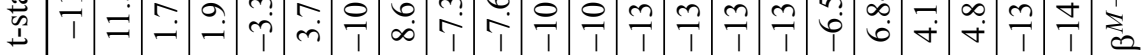

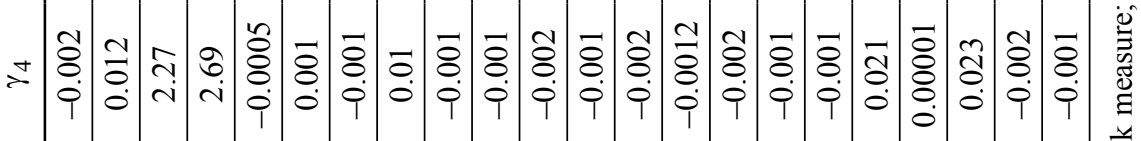
๘

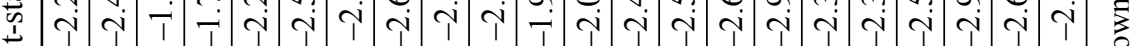

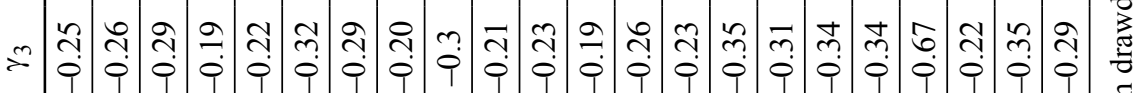
$\sim$ च

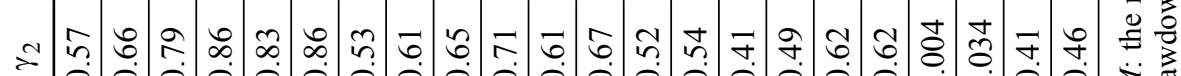

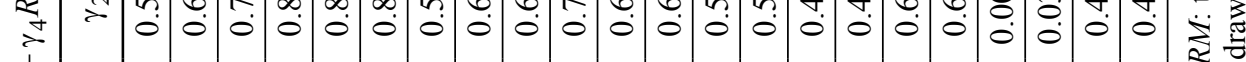

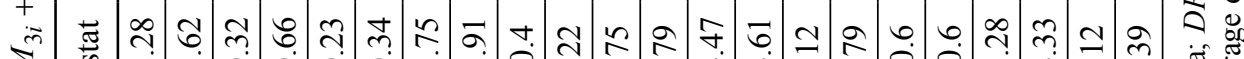

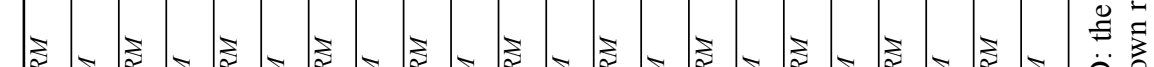

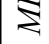
至

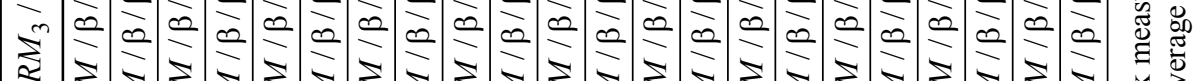

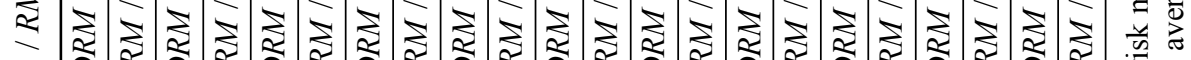
๙ 王

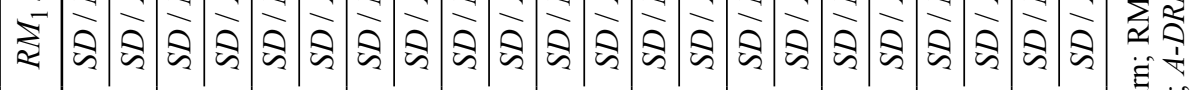

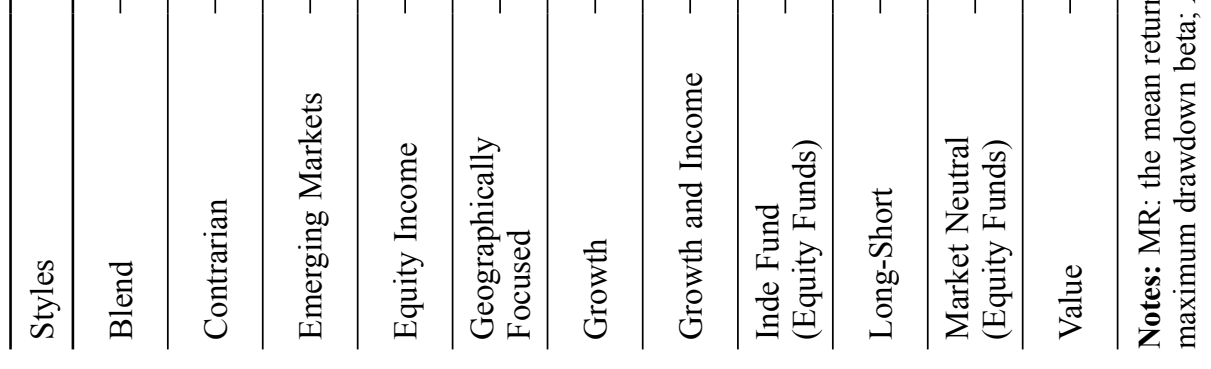


The return spreads spanned by $D R M$ betas are larger than those spanned by beta. Moreover, we obtain the relative spread by dividing the spread in monthly mean returns by the spread in the risk measure, which is 0.88 in the case of portfolios ranked by betas and 1.015 in the case of portfolios ranked by $D R M$ betas; that is, mean returns are more sensitive to spreads in $D R M$ betas than equal spreads in betas.

Panels B, C, D, E, F, G, I, J, K, and L of Table 7 also show same results so that there seems to be a considerable difference in the spread of two risk measures of portfolios 1 and 3 in the styles. In fact, the average betas of portfolio 1 are larger than the average betas of portfolio 3 and the average $D R M$ betas of portfolio 1 are larger than the average $D R M$ betas of portfolio 3. Moreover, Panels B, C, D, E, F, G, I, J, K, and L of Table 7 show that return spreads spanned by the $D R M$ betas are higher than those spanned by beta. Finally, as evidenced by the relative spreads, mean returns are more sensitive to spreads in the DRM betas than equal spreads in beta.

Table 7. Economic significant on management styles

\begin{tabular}{|c|c|c|c|c|c|}
\hline \multicolumn{6}{|c|}{ Panel A: All Management Styles } \\
\hline $\mathrm{P} 1$ & 1.08 & 1.1 & 1.5 & 1.3 & 1.6 \\
\hline $\mathrm{P} 2$ & 0.62 & 0.45 & 1.23 & 1.09 & 0.66 \\
\hline P3 & 0 & 0.14 & 0.07 & 0.02 & 0.31 \\
\hline Spread P1-P3 & 1.08 & 0.96 & 1.43 & 1.27 & 1.29 \\
\hline Annualized spread & & 0.82 & & & 0.91 \\
\hline Relative spread & & 0.88 & & & 1.015 \\
\hline \multicolumn{6}{|c|}{ Panel B: Blend } \\
\hline P1 & 0.14 & -0.09 & 0.36 & 0.34 & 0.35 \\
\hline $\mathrm{P} 2$ & 0.09 & 0.11 & 0.26 & 0.21 & 0.20 \\
\hline $\mathrm{P} 3$ & -0.15 & 0.14 & 0.05 & 0.01 & -0.05 \\
\hline Spread P1-P3 & 0.29 & -0.23 & 0.31 & 0.33 & 0.3 \\
\hline Annualized spread & & 0.64 & & & 0.70 \\
\hline Relative spread & & 0.79 & & & 0.9 \\
\hline \multicolumn{6}{|c|}{ Panel C: Contrarian } \\
\hline $\mathrm{P} 1$ & 1.18 & 1.01 & 1.31 & 1.24 & 2.1 \\
\hline $\mathrm{P} 2$ & 0.81 & 0.201 & 1.06 & 1.01 & 0.66 \\
\hline P3 & -0.075 & -0.21 & 0.12 & 0.101 & 0.15 \\
\hline Spread P1-P3 & 1.105 & 0.8 & 1.19 & 1.139 & 1.95 \\
\hline Annualized spread & & 0.60 & & & 0.65 \\
\hline Relative spread & & 0.72 & & & 1.71 \\
\hline \multicolumn{6}{|c|}{ Panel D: Emerging Markets } \\
\hline $\mathrm{P} 1$ & 1.04 & 0.41 & 1.14 & 1.11 & 0.84 \\
\hline $\mathrm{P} 2$ & 0.99 & 0.21 & 1.08 & 1.01 & 0.32 \\
\hline
\end{tabular}




\begin{tabular}{lccccc}
\hline P3 & -0.064 & 0.27 & 0.012 & 0.002 & 0.65 \\
\hline Spread P1-P3 & 0.976 & 0.14 & 1.128 & 1.108 & 0.19 \\
\hline Annualized spread & \multicolumn{5}{c}{0.26} \\
\hline Relative spread & 0.22 & 0.17 \\
\hline \multicolumn{5}{c}{ Panel E: Equity Income } \\
\hline P1 & 0.56 & 0.23 & 0.63 & 0.58 & 0.74 \\
\hline P2 & 0.31 & 0.24 & 0.37 & 0.32 & 0.27 \\
\hline P3 & -0.009 & 0.34 & 0.009 & 0.006 & 0.03 \\
\hline Spread P1-P3 & 0.551 & -0.11 & 0.621 & 0.574 & 0.71 \\
\hline Annualized spread & \multicolumn{7}{c}{0.15} & 0.38 \\
\hline Relative spread & -0.19 & & 1.23 \\
\hline
\end{tabular}

\begin{tabular}{|c|c|c|c|c|c|}
\hline \multicolumn{6}{|c|}{ Panel F: Geographically Focused (Equity Funds) } \\
\hline P1 & 0.29 & 0.034 & 0.35 & 0.31 & 0.22 \\
\hline P2 & 0.11 & 0.09 & 0.28 & 0.23 & 0.20 \\
\hline $\mathrm{P} 3$ & -0.14 & 0.45 & 0.09 & 0.07 & 0.12 \\
\hline Spread P1-P3 & 0.15 & -0.416 & 0.26 & 0.24 & 0.1 \\
\hline Annualized spread & & 0.24 & & & 0.27 \\
\hline Relative spread & & -2.77 & & & 0.416 \\
\hline \multicolumn{6}{|c|}{ Panel G: Growth } \\
\hline P1 & 0.14 & 1.1 & 0.19 & 0.16 & 1.2 \\
\hline $\mathrm{P} 2$ & 0.07 & 0.82 & 0.13 & 0.10 & 0.83 \\
\hline P3 & 0.02 & 0.22 & 0.02 & 0.021 & 0.1 \\
\hline Spread P1-P3 & 0.12 & 0.88 & 0.14 & 0.139 & 1.1 \\
\hline Annualized spread & & 0.44 & & & 0.56 \\
\hline Relative spread & & 7.16 & & & 7.91 \\
\hline \multicolumn{6}{|c|}{ Panel H: Growth and Income } \\
\hline P1 & 0.11 & 0.75 & 0.14 & 0.12 & 0.8 \\
\hline $\mathrm{P} 2$ & 0.05 & 0.24 & 0.08 & 0.06 & 0.31 \\
\hline P3 & 0.022 & 0.19 & 0.03 & 0.026 & 0.2 \\
\hline Spread P1-P3 & 0.088 & 0.56 & 0.11 & 0.094 & 0.6 \\
\hline Annualized spread & & 0.55 & & & 0.56 \\
\hline Relative spread & & 6.36 & & & 6.38 \\
\hline \multicolumn{6}{|c|}{ Panel I: Inde Fund (Equity Funds) } \\
\hline $\mathrm{P} 1$ & 0.09 & 0.206 & 0.15 & 0.1 & 0.21 \\
\hline $\mathrm{P} 2$ & 0.01 & 0.101 & 0.04 & 0.03 & 0.17 \\
\hline P3 & -0.004 & 0.09 & 0.008 & 0.004 & 0.15 \\
\hline Spread P1-P3 & 0.094 & 0.116 & 0.142 & 0.096 & 0.06 \\
\hline
\end{tabular}


End of Table 7

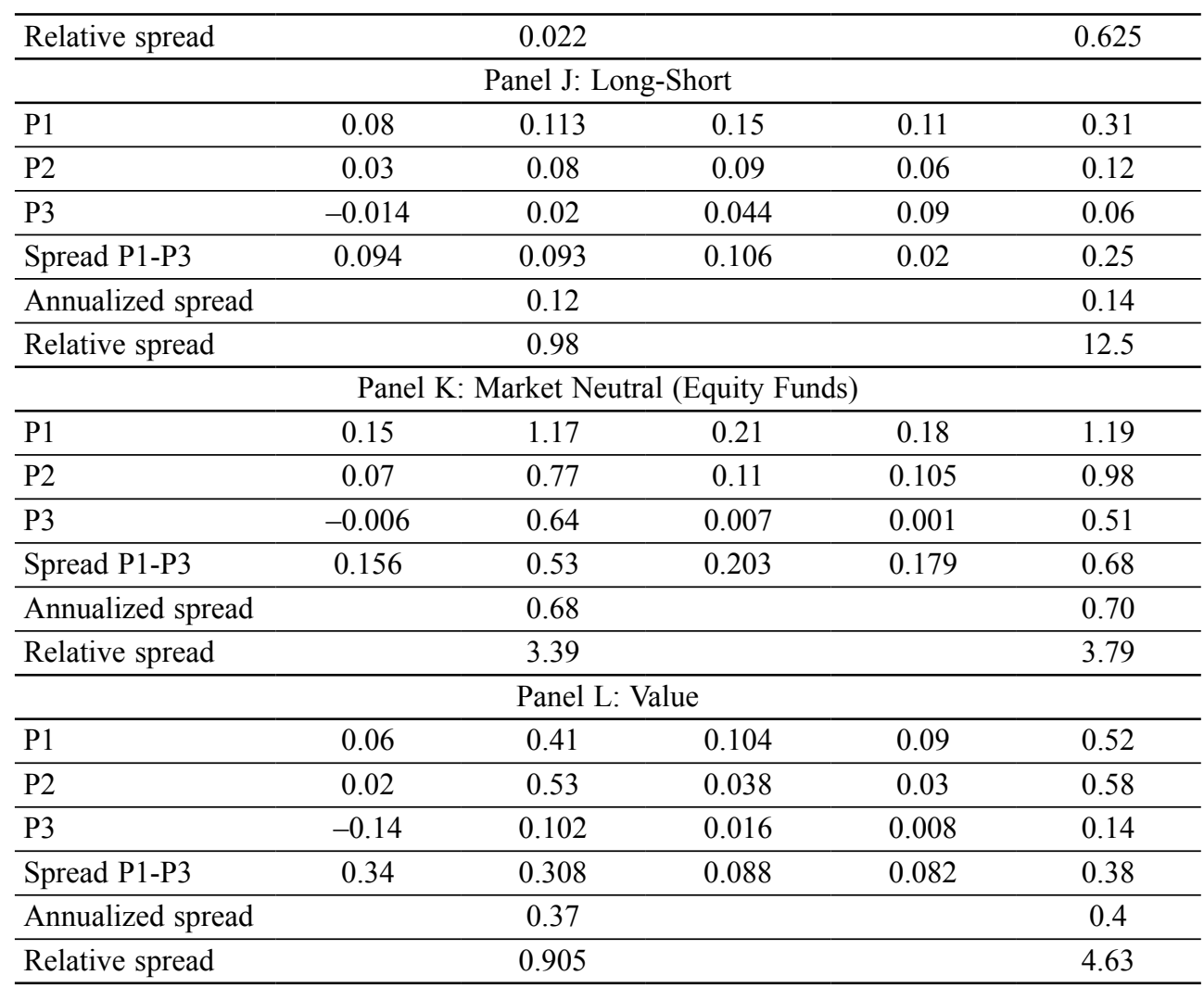

Notes: Portfolio 1 (P1) is the riskiest portfolio (the largest betas); Portfolio 3 (P3) is the least risky portfolio (the lowest betas); MR: the mean return in percent; $\beta$ : the beta; $\beta^{M-D R M}$ : the maximum drawdown beta; $\beta^{A-D R M}$ : the average drawdown beta. Relative spread is the ratio between the Spread $\mathrm{P} 1-\mathrm{P} 3$ in mean returns and the Spread P1-P3 in the measure.

The second method of robustness check is due to the existence of dead and outlier funds, which imposes bias on the process of our analysis. Thus, we first decompose our sample into two periods of 2000 to 2006 and 2006 to 2011, and then repeat our analysis similar to our previous analysis. In addition, we consider a five-year period from 1995 to 2000 and again run the pooled model as reported in Table 8. In general, the results of these tests are similar to the In-sample period, in which our findings clearly support from the drawdown betas versus the traditional beta.

\subsection{Expected returns on fund}

As a conclusion at this point, our results detect that, when considering the joint sample of the styles, (1) the DRM measures outperform the traditional measures; (2) the best betas that describe the cross section of returns are the DRM betas (Table 3); (3) the only measures that significantly describe the cross section of returns, when all risk measures 
are jointly considered, are the $D R M$ measures (Table 4); and (4) mean returns are more sensitive to variations in $D R M$ betas than to equal variations in traditional beta (Table 7). (5) the $D R M$ betas are the best measure that describes the cross section of returns (Table 5); (6) when the measures considered jointly, none of the two traditional measures significantly describes the cross section of returns, and only two DRM measures do (Table 6); and (7) mean returns are more sensitive to variations in DRM beta than equal variations in traditional beta.

Table 8. Result of robustness check

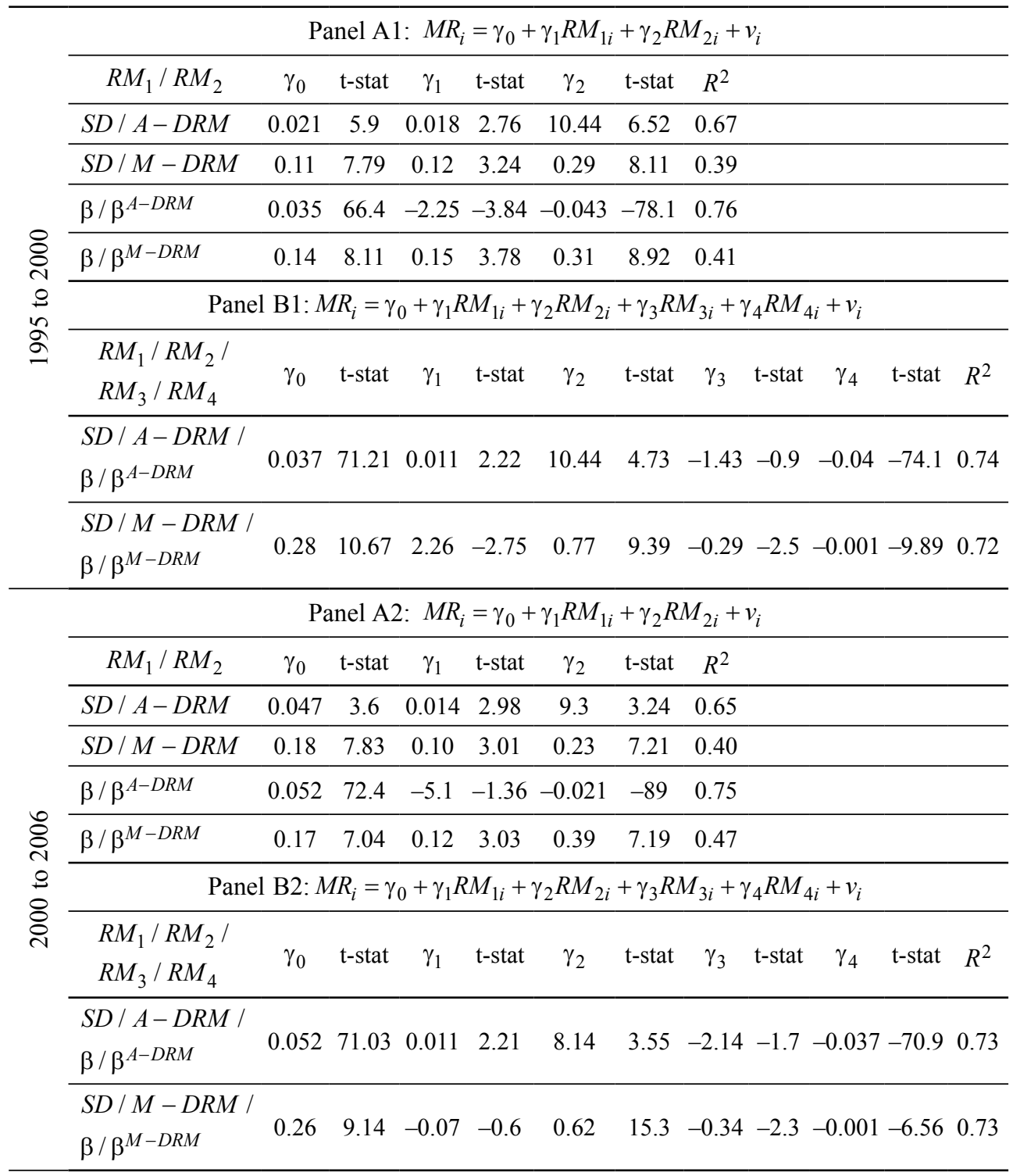


End of Table 8

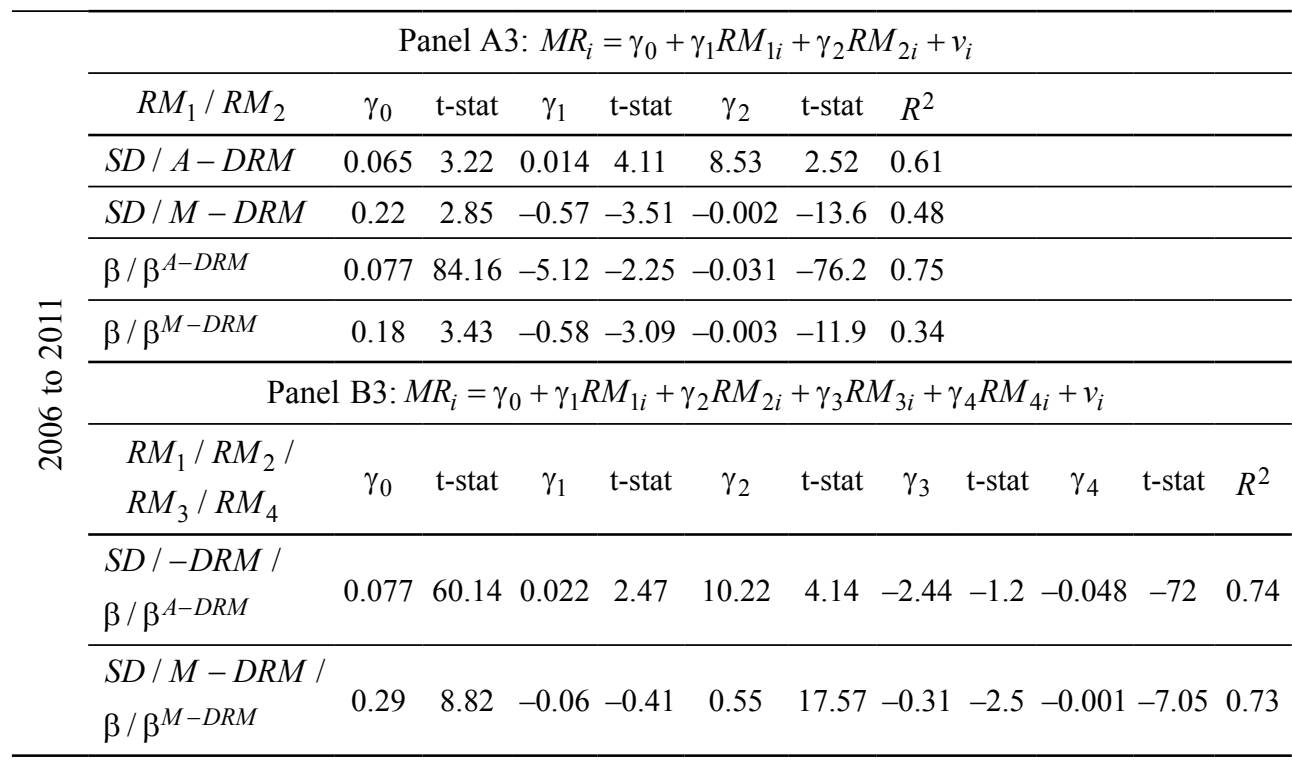

Notes: MR: the mean return; RM: the risk measure; SD: the standard deviation; $\beta$ : the beta; $D R M$ : the maximum drawdown risk measure; $\beta^{M-D R M}$ : the maximum drawdown beta; $A-D R M$ : the average drawdown risk measure; $\beta^{A-D R M}$ : the average drawdown beta.

We turn now to compare the expected returns generated by the $C A P M$ given by (5), and the alternative models based on the DRM betas (MD-CAPM) and (AD-CAPM) given by (11) and (17). In both cases, a risk-free rate of 0.20 and a market risk premium of $6 \%$ are used. The estimates are reported in Table 9, where we find two interesting findings. First, the average traditional beta is smaller than the $D R M$ betas in all the styles. Second, the average expected returns in $D R M$-based $C A P M$ models are higher than the CAPM.

\subsection{A final digression: why do the $D R M$ betas work?}

The superiority of the $D R M$ betas versus beta in describing the cross section of fund returns is a somewhat surprising finding to some. In this section, we justify the plausibility of our empirical results. First, an investor does not like volatility; rather he only likes drawdown volatility. He does not have attention to funds which explain jumps higher than the mean; he has attention to funds which explain frequent and large jumps less than the mean. In fact, investors are not worry about getting the return greater than their minimum acceptable one; rather they are worry about getting the return lower than their minimum acceptable one. Moreover, the superiority of $D R M$ betas can be related to the contagion impacts in fund markets. Note that in the MV framework, the suitable risk measure is the beta when markets are integrated, and the standard deviation when markets are segmented. The superiority of the $D R M$ betas can thus be described by the fact which markets are more integrated on the $D R M$ than the upside risk measure due to the contagion impacts, an interpretation consistent with Galagedera (2007), and Fortin and Hlouskova (2011). 
Table 9. Expected returns on funds

\begin{tabular}{lcccccc}
\hline Management Styles & $\hat{\beta}$ & $\beta^{A-\hat{D} R M}$ & $\beta^{M-\hat{-D R M}}$ & CAPM & AD-CAPM & MD-CAPM \\
\hline Blend & 0.008 & 0.021 & 0.012 & 0.20048 & 0.20126 & 0.20072 \\
\hline Contrarian & -0.44 & 0.042 & -0.000004 & 0.17337 & 0.20252 & 0.2 \\
\hline Emerging Markets & 0.007597 & 0.04611 & 0.040036 & 0.200456 & 0.202767 & 0.202402 \\
\hline Equity Income & 0.006765 & 0.2816 & 0.27106 & 0.200406 & 0.216896 & 0.216264 \\
\hline Geographically & 0.007777 & 0.43421 & 0.41377 & 0.200467 & 0.226053 & 0.224826 \\
Focused & & & & & & \\
\hline Growth & 0.010236 & 0.41271 & 0.39575 & 0.200614 & 0.224763 & 0.223745 \\
\hline Growth and Income & 0.534217 & 0.892411 & 0.864031 & 0.232053 & 0.253545 & 0.251842 \\
\hline Inde Fund & 0.019687 & 0.24291 & 0.227907 & 0.201181 & 0.214575 & 0.213674 \\
\hline Long-Short & 0.194085 & 0.44750 & 0.429199 & 0.211645 & 0.22685 & 0.225752 \\
\hline Market Neutral & 0.109139 & 0.45321 & 0.429085 & 0.206548 & 0.227193 & 0.225745 \\
\hline Value & 0.026644 & 0.30112 & 0.283456 & 0.244359 & 0.218067 & 0.261126 \\
\hline All Management & 0.107404 & 0.32498 & 0.308594 & 0.206444 & 0.219499 & 0.218516 \\
Styles & & & & & & \\
\hline
\end{tabular}

Notes: $\hat{\beta}$ : the estimated beta; $\beta^{M-\hat{D} R M}$ : the estimated maximum drawdown beta; $\beta^{A-\hat{D R M}}$ : the estimated average drawdown beta. Expected returns are estimated by Eq. (5), (11) and (17), a risk-free rate of 0.20 and a market risk premium of $6 \%$.

\section{Conclusion}

The traditional beta, $C A P M$ and their behavioral model $(M V B)$ have been widely used but also extensively debated over the past 40 years. Most of the debates versus beta focus on comparing the ability of this coefficient rather than alternative risk measures to describe the cross section of assets' return. We found that the data on US equity-based mutual funds' management styles support from the $D R M$ betas and their relevant pricing models, (MD-CAPM) and (AD-CAPM), rather than beta and CAPM. We generated a parallel between the traditional framework in terms of $M V B$, beta, and $C A P M$, and a replacement framework in terms of the $D R M$; that is, on $M D B$, the $D R M$ and $A-D R M$ betas, and their pricing models. We proposed some methods to estimate the $D R M$ betas and to extend them into pricing models, (MD-CAPM) and (AD-CAPM). Our findings support from the $D R M$ versus the traditional measures and show that mean returns are much more sensitive to spreads in $D R M$ betas than equal spreads in beta. Moreover, unlike the $C A P M$, the drawdown $C A P M$ plausibly generates a higher expected return.

However, we believe that our suggested measures are able to be replaced with the traditional measures, where financial markets experience a depression. It seems that our suggested measures and models provide a better framework to evaluate portfolio in asymmetric condition. 
Finally, we investigate the traditional approach of $M V B$, beta, and $C A P M$, and suggest replacing it with alternative approach of $M D B$, the $D R M$ betas, and their relevant pricing models.

\section{References}

Alexander, G. J.; Baptista, A. M. 2006. Portfolio selection with a drawdown constraint, Journal of Banking and Finance 30(11): 3171-3189. http://dx.doi.org/10.1016/j.jbankfin.2005.12.006

Chekhlov, A.; Uryasev, S.; Zabarankin, M. 2005. Drawdown measure in portfolio optimization, International Journal of Theoretical and Applied Finance 8(1): 13-58.

http://dx.doi.org/10.1142/S0219024905002767

Dacorogna, M. M.; Gençay, R.; Müller, U. A.; Pictet, O. V. 2001. Effective return, risk aversion and drawdowns, Physica A 289(1-2): 229-248. http://dx.doi.org/10.1016/S0378-4371(00)004623

Dichtl, H.; Drobetz, W. 2011. Portfolio insurance and prospect theory investors: popularity and optimal design of capital protected financial products, Journal of Banking \& Finance 35(7): 1683-1697. http://dx.doi.org/10.1016/j.jbankfin.2010.11.012

Eling, M.; Schuhmacher, F. 2007. Does the choice of performance measure influence the evaluation of hedge funds?, Journal of Banking \& Finance 31(9): 2632-2647.

http://dx.doi.org/10.1016/j.jbankfin.2006.09.015

Fortin, I.; Hlouskova, J. 2011. Optimal asset allocation under linear loss aversion, Journal of Banking \& Finance 35(11): 2974-2990. http://dx.doi.org/10.1016/j.jbankfin.2011.03.023

Galagedera, D. U. A. 2007. An alternative perspective on the relationship between downside beta and CAPM beta, Emerging Markets Review 8(1): 4-19.

http://dx.doi.org/10.1016/j.ememar.2006.09.010

Gilli, M.; Schumann, E. 2009. An Empirical Analysis of Alternative Portfolio Selection Criteria [online], [cited 19 March 2009]. Available from Internet: http://ssrn.com/abstract=1365167

Grossman, S. J.; Zhou, Z. 1993. Optimal investment strategies for controlling drawdowns, Mathematical Finance 3(3): 241-276. http://dx.doi.org/10.1111/j.1467-9965.1993.tb00044.x

Hamelink, F.; Hoesli, M. 2004. Maximum drawdown and the allocation to real estate, Journal of Property Research 21(1): 5-29. http://dx.doi.org/10.1080/0959991042000217903

Schuhmacher, F.; Eling, M. 2011. Sufficient conditions for expected utility to imply drawdownbased performance rankings, Journal of Banking \& Finance 35(9): 2311-2318.

http://dx.doi.org/10.1016/j.jbankfin.2011.01.031

Mohammad Reza TAVAKOLI BAGHDADABAD was born in Iran in 1976. His research areas are Investment, Portfolio Management and Performance Evaluation.

Fauzias Mat NOR was born in 1959. She is a Professor in National University of Malaysia.

Izani IBRAHIM was born in 1958. He is a Professor in National University of Malaysia. 